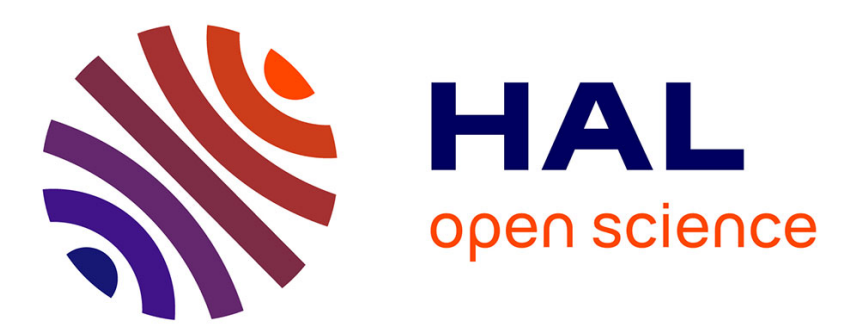

\title{
Core-shell structure of chemically synthesised FePt nanoparticles: a comparative study
}

Michael Delalande, Pierre R. Marcoux, Peter Reiss, Yves Samson

\section{To cite this version:}

Michael Delalande, Pierre R. Marcoux, Peter Reiss, Yves Samson. Core-shell structure of chemically synthesised FePt nanoparticles: a comparative study. Journal of Materials Chemistry, 2007, 17 (16), pp.1579-1588. 10.1039/b614209e . cea-02528443

\section{HAL Id: cea-02528443 https://hal-cea.archives-ouvertes.fr/cea-02528443}

Submitted on 1 Apr 2020

HAL is a multi-disciplinary open access archive for the deposit and dissemination of scientific research documents, whether they are published or not. The documents may come from teaching and research institutions in France or abroad, or from public or private research centers.
L'archive ouverte pluridisciplinaire HAL, est destinée au dépôt et à la diffusion de documents scientifiques de niveau recherche, publiés ou non, émanant des établissements d'enseignement et de recherche français ou étrangers, des laboratoires publics ou privés. 
Core-shell structure of chemically synthesised FePt nanoparticles: a comparative study

Michaël Delalande, Pierre R. Marcoux, Peter Reiss and Yves Samson

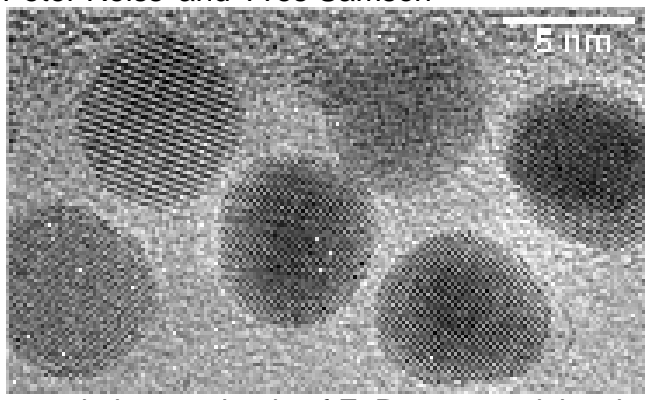

We conducted a comparative study about solution synthesis of FePt nanoparticles through different chemical processes, 5 using four "hot soap methods" and one polyol process. 


\title{
Core-shell structure of chemically synthesised FePt nanoparticles: a comparative study $\dagger$
}

\author{
Michaël Delalande, ${ }^{a}$ Pierre R. Marcoux, ${ }^{b}$ Peter Reiss ${ }^{* b}$ and Yves Samson* ${ }^{a}$ \\ Receipt/Acceptance Data [DO NOT ALTER/DELETE THIS TEXT] \\ 10 Publication data [DO NOT ALTER/DELETE THIS TEXT] \\ DOI: 10.1039/b000000x [DO NOT ALTER/DELETE THIS TEXT]
}

We carried out solution synthesis of FePt nanoparticles through different chemical methods, using four "hot soap methods", i.e. the particle formation in the presence of surfactant molecules at high temperatures, and one polyol process. Structural and magnetic properties of the as-made particles

15 pointed to a core-shell structure for the particles prepared with hot soap methods, with an irondepleted core surrounded by a pure iron shell. Such a structure has an impact on the magnetic properties of as-made particles since $\mathrm{Fe}$ atoms from shell are oxidised and non magnetic. We proved however that iron atoms of this shell are available during the formation of the ordered phase upon annealing: $\mathrm{L} 1_{0}$ phase for small particles, $\mathrm{L}_{2}$ for bigger ones. In contrast, the core-shell 20 structure was not observed in the case of nanoparticles synthesised according to the polyol process. This outlines the key role of the stabilising ligands, long alkyl chain surfactants in the former case and tetraethylene glycol in the latter.

\section{Introduction}

Chemical methods have been widely used to produce 25 nanosized materials due to their straightforward nature and their potential to prepare large quantities of the final product. ${ }^{1}$ Furthermore, they provide particles that are easily dispersible in liquid media, and therefore give the opportunity to fabricate nanostructured devices through self-assembly. ${ }^{2}$

30 The synthesis of discrete magnetic nanoparticles with sizes ranging from to 2 to $20 \mathrm{~nm}$ is of significant importance, because of their applications in Tbit.in ${ }^{-2}$ magnetic storage devices $^{3}$ and in biotechnologies. ${ }^{4}$ The superparamagnetism limit makes it necessary to use highly anisotropic materials. 35 Among magnetic metallic alloys, the FePt alloy in the $\mathrm{L}_{0}$ phase is a prominent candidate. This ordered phase has indeed a very high uniaxial anisotropy, $\mathrm{K}_{\mathrm{u}}=7 \times 10^{6} \mathrm{~J} / \mathrm{m}^{3}$, so that the critical diameter, below which thermal fluctuations induce random switching of the magnetisation direction, is as small 40 as $3.5 \mathrm{~nm}$.

For this reason, many processes for the chemical synthesis of nanometer-sized FePt nanoparticles have been developed. First of all these reactions aim at monodisperse particles, in order to facilitate subsequent self-assembly, and to yield 45 homogeneous magnetic properties of particles. Secondly, these reactions should provide size-tunable particles, with a diameter large enough compared to the critical diameter. Thirdly, the stoichiometry should be as close to $\mathrm{Fe}_{50} \mathrm{Pt}_{50}$ as possible since the chemically ordered $\mathrm{L} 1_{0}$ phase, with a high

${ }^{a}$ CEA, DRFMC, Nanostructure and Magnetism, 17 rue des Martyrs 38054 Grenoble, France. Fax: 334387851 97; Tel: 334387835 62; E-mail: yves.samson@cea.fr

${ }^{b}$ CEA, DRFMC, SPrAM (UMR 5819 CNRS-CEA-UJF), 17 rue des Martyrs 38054 Grenoble, France Fax: 3343878 50 97; Tel: 3343878 97 19; E-mail:peter.reiss@cea.fr

$\dagger$ Electronic Supplementary Information (ESI) available: X-Ray diffractograms of as-made and annealed nanoparticles; TEM micrographs and diameter distribution histograms of as-made particles. See http://dx.doi.org/10.1039/b000000x/
50 magnetocrystalline anisotropy, includes as many $\mathrm{Fe}$ atoms as $\mathrm{Pt}$ atoms. Finally, the as-made particles should be readily dispersible in common solvents, because self-assembly phenomena are sensitive to aggregation. Furthermore, in some cases size-selection steps are necessary and such processes 55 require also a good solubility. The first reported protocol mentioned in 2000 the synthesis of FePt nanoparticles in a high-boiling coordinating solvent. It was later called "hot soap method" since the formation of metallic Fe and Pt atoms was performed in presence of surfactant molecules. ${ }^{5}$ A similar 60 method was subsequently extended to the synthesis of another binary alloy $(\mathrm{CoPt}),{ }^{6}$ and then to ternary alloys (FePtAg). ${ }^{7}$

Most of the solution synthesis methods of $\mathrm{FePt}$ nanoparticles are based on the transformation of an iron precursor and a platinum precursor into the metallic state, in ${ }_{65}$ presence of two surfactant molecules (one that preferentially binds to Fe surface atoms, another one for Pt). The latter are in charge with stabilising metallic nuclei in solution by preventing aggregation during growth. Precursors may be either organometallic $\left(\mathrm{Fe}^{0}\right.$ in iron pentacarbonyl for example) 70 or ionic (e. g. $\mathrm{Pt}^{\mathrm{II}}$ in platinum acetylacetonate). The use of an oxidised metal as a precursor implies the presence of a reducing agent, a strong one if $\mathrm{Fe}^{\mathrm{II}}$ and $\mathrm{Pt}^{\mathrm{II}}$ have to be reduced, ${ }^{8}$ a milder one if just $\mathrm{Pt}^{\mathrm{II}}$ needs to be reduced. Due to their higher reduction potential $(1.2 \mathrm{~V}$ vs. $-0.4 \mathrm{~V})$, platinum 75 salts can easier be reduced as compared to iron salts. In some cases, the reducing agent may be the solvent, ${ }^{9}$ or one of the metallic precursors. ${ }^{10}$ As a conclusion, let us notice that there are very few hot soap reactions involving an organometallic $\mathrm{Pt}^{0}$ precursor.

80 Since iron pentacarbonyl is highly flammable and very toxic, alternative methods have soon been developed, in which this Fe precursor was replaced by an ionic iron precursor such as $\mathrm{FeCl}_{2}$ or $\mathrm{Fe}(\mathrm{acac})_{2}$. In addition, with the goal to facilitate chemical ordering of the FePt alloy particles during the ${ }_{85}$ synthesis, attempts were made to slow down the growth 
Table 1 The different chemical syntheses investigated in the present study.

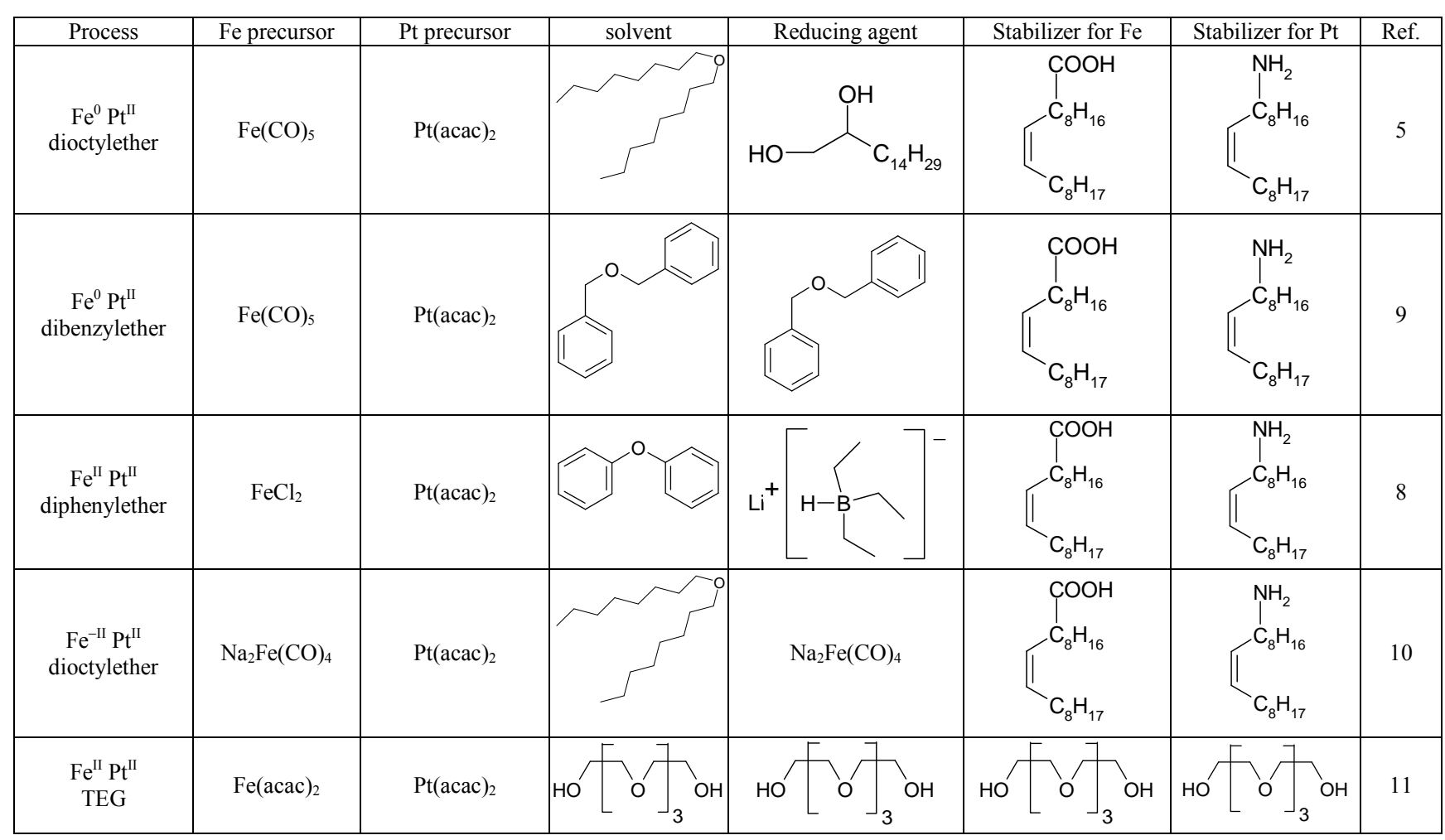

kinetics. This led to the development of polyol processes. A kinetic control is indeed easier to achieve in a polyol (ethylene glycol, EG, or tetraethylene glycol, TEG, for example), acting simultaneously as the solvent, the reducing 90 agent and the stabilising ligand. ${ }^{11}$

In the present study, we compared four hot soap methods and a polyol process using TEG. These five methods are summarised in Table 1. The first process, using $\mathrm{Fe}^{0}$ and $\mathrm{Pt}^{\mathrm{II}}$ in dioctylether, was the first synthesis of $\mathrm{FePt}$ nanoparticles 95 described, and is still today the most common in literature. In the second method, dibenzylether acts simultaneously as solvent and reducing agent for the Pt precursor. The third process uses an ionic precursor of iron and therefore requires a strong reducing agent, lithium hydride. In the fourth method, 100 the most recent one, the Pt precursor is reduced by the $\mathrm{Fe}$ precursor. Finally, in the polyol process, TEG is at the same time the solvent, the reducing agent and the stabilising ligand. For every method, we will characterize structurally and magnetically as-made and annealed particles, so that we can

105 highlight the major differences between all synthesis reactions.

\section{Experimental}

\section{Nanoparticles' preparation by the $\mathrm{Fe}^{0} \mathrm{Pt}^{I I}$ dioctylether $\operatorname{method~}^{5}$}

110 A stirred mixture of $\mathrm{Pt}(\mathrm{acac})_{2}(197 \mathrm{mg} ; 0.5 \mathrm{mmol})$ and 1,2hexadecanediol $(388 \mathrm{mg} ; 1.5 \mathrm{mmol})$ in dioctylether $(15 \mathrm{~mL}$; $12.105 \mathrm{~g}$ ) is heated under argon to $100^{\circ} \mathrm{C}$ with a $12^{\circ} \mathrm{C} / \mathrm{min}$ rate. After 15 minutes at $100^{\circ} \mathrm{C}$, all the powder has been dissolved and the solution is slightly yellow coloured. Then a 115 solution of $\mathrm{Fe}(\mathrm{CO})_{5}(196 \mathrm{mg} ; 1 \mathrm{mmol})$, oleylamine $(134 \mathrm{mg}$;
$0.5 \mathrm{mmol})$ and oleic acid $(141 \mathrm{mg} ; 0.5 \mathrm{mmol})$ in dioctylether $(5 \mathrm{~mL} ; 4.035 \mathrm{~g})$ is injected into the solution containing $\mathrm{Pt}(\mathrm{acac})_{2}$ while vigorously stirring. As soon as the reaction temperature comes back to $100^{\circ} \mathrm{C}$, temperature is set to $295^{\circ} \mathrm{C}$ 120 with a $10^{\circ} \mathrm{C} / \mathrm{min}$ rate. After 30 minutes of reflux, the reaction mixture is cooled down to room temperature. Then $80 \mathrm{~mL}$ of anhydrous ethanol are added, in order to precipitate the particles. They are centrifuged, then dissolved in toluene (20 $\mathrm{mL}$ ) containing both stabilising ligands (oleic acid and 125 oleylamine; $50 \mu \mathrm{L}$ of each). $40 \mathrm{~mL}$ of anhydrous ethanol are added for the second precipitation step. After centrifugation, the FePt nanoparticles are dispersed in toluene $(20 \mathrm{~mL})$ with both surfactants $(50 \mu \mathrm{L}$ of each). The long-term stability of the obtained black dispersion is more than 1 year without a 130 sign of precipitation.

\section{Nanoparticles' preparation by the $F^{0} P^{I I}$ dibenzylether method $^{9}$}

A stirred mixture of $\operatorname{Pt}(\mathrm{acac})_{2}(296 \mathrm{mg} ; 0.75 \mathrm{mmol})$ and dibenzylether $(15 \mathrm{~mL} ; 15.645 \mathrm{~g})$ is heated under argon from 135 room temperature to $240^{\circ} \mathrm{C}$ with a $5^{\circ} \mathrm{C} / \mathrm{min}$ rate. When the temperature of the solution reaches $100^{\circ} \mathrm{C}, \mathrm{Fe}(\mathrm{CO})_{5}(294 \mathrm{mg}$; $1.5 \mathrm{mmol})$, oleylamine (1.607 $\mathrm{g} ; 6 \mathrm{mmol})$ and oleic acid $(1.697 \mathrm{~g} ; 6 \mathrm{mmol})$ are injected. The temperature is then kept at $240^{\circ} \mathrm{C}$ for 1 hour, raised to $280^{\circ} \mathrm{C}$ with a $5^{\circ} \mathrm{C} / \mathrm{min}$ rate and 140 maintained at this value for 2 hours. During this reflux stage, a colourless liquid is distilled from reaction mixture. This liquid is composed of toluene and benzaldehyde. The reaction mixture is subsequently cooled down to room temperature and the particles are precipitated by adding $80 \mathrm{~mL}$ of anhydrous 145 ethanol. They are purified in the same way as in the $\mathrm{Fe}^{0} \mathrm{Pt}^{I I}$ dioctylether method. 
Spectroscopic data of distilled fraction. FTIR: $v_{\max } / \mathrm{cm}^{-1} 3028$, 2922 and 2856 (toluene), 2816 and 2734 (benzaldehyde), 1702vs (CO benzaldehyde), 1596 (benzaldehyde), 1496 150 (toluene), 1202s (benzaldehyde), 1076, 1030 and $728 \mathrm{vs}$ (toluene). NMR: $\delta_{\mathrm{H}}\left(200 \mathrm{MHz} ; \mathrm{CDCl}_{3} ; \mathrm{Me}_{4} \mathrm{Si}\right) 2.24\left(\mathrm{~s}, \mathrm{CH}_{3}\right.$ of toluene), 7.06, 7.09, 7.13, 7.15, 7.19, 7.20, 7.26, 7.30, 7.33 (m, aromatic protons of toluene and benzaldehyde), 7.67 (dd, $\mathrm{CH}=\mathrm{CH}-\mathrm{C}-\mathrm{CHO}), 9.77$ (s, $\mathrm{Ar}-\mathrm{CHO})$.

155 Nanoparticles' preparation by the $\mathrm{Fe}^{I I} \boldsymbol{P t}^{I I}$ diphenylether method $^{8}$

Diphenylether $(25 \mathrm{~mL} ; 26.825 \mathrm{~g})$ is molten (m.p. $\left.25-27^{\circ} \mathrm{C}\right)$ and then added to $\mathrm{Pt}(\mathrm{acac})_{2}$ (204 $\left.\mathrm{mg} ; 0.52 \mathrm{mmol}\right), \mathrm{FeCl}_{2}(104$ $\mathrm{mg} ; 0.52 \mathrm{mmol}$ ) and 1,2-hexadecanediol (535 mg; 2.07 $160 \mathrm{mmol})$. The resulting mixture is stirred under argon and heated to $100^{\circ} \mathrm{C}$. Oleylamine $(139 \mathrm{mg} ; 0.52 \mathrm{mmol})$ and oleic acid $(150 \mathrm{mg} ; 0.52 \mathrm{mmol})$ are added at $100^{\circ} \mathrm{C}$, causing the solution turning from yellow to grey. Then reaction mixture is heated to $240^{\circ} \mathrm{C}$ with a $5^{\circ} \mathrm{C} / \mathrm{min}$ rate, and lithium 165 triethylborohydride solution ( $1 \mathrm{M}$ in THF; $2.5 \mathrm{~mL} ; 2.5 \mathrm{mmol}$ ) is added dropwise. After completed hydride addition, the reaction temperature is increased to $258^{\circ} \mathrm{C}$, and kept at this value for $20 \mathrm{~min}$. The solution is cooled down to room temperature, and $90 \mathrm{~mL}$ of anhydrous ethanol are added for a

170 first precipitation step. Further purification is carried out as described in the nanoparticles' preparation by the $\mathrm{Fe}^{0} \mathrm{Pt}^{I I}$ dioctylether method.

Nanoparticles' preparation by the $\mathrm{Fe}^{-I I} \mathrm{Pt}^{I I}$ dioctylether method $^{10}$

175 Collman's reagent, $\mathrm{Na}_{2} \mathrm{Fe}(\mathrm{CO})_{4} .5\left(\mathrm{C}_{4} \mathrm{H}_{8} \mathrm{O}_{2}\right) \quad(173 \mathrm{mg} ; 0.5$ mmol) is mixed with $\mathrm{Pt}(\mathrm{acac})_{2}(197 \mathrm{mg} ; 0.5 \mathrm{mmol})$, oleylamine $(535 \mathrm{mg} ; 2 \mathrm{mmol})$ and oleic acid $(565 \mathrm{mg} ; 2$ $\mathrm{mmol})$ in dioctylether $(20 \mathrm{~mL} ; 16.140 \mathrm{~g})$. The reaction mixture is stirred under argon and heated from room

180 temperature to $100^{\circ} \mathrm{C}$ with a $10^{\circ} \mathrm{C} / \mathrm{min}$ rate. The temperature is then kept at this value for $25 \mathrm{~min}$ before raising it to $295^{\circ} \mathrm{C}$ with a $10^{\circ} \mathrm{C} / \mathrm{min}$ rate and maintaining it there for $30 \mathrm{~min}$. After cooling down the reaction mixture to room temperature, anhydrous ethanol $(80 \mathrm{~mL})$ is added to achieve precipitation 185 of the particles, followed by the purification as described before (see Nanoparticles preparation by the $\mathrm{Fe}^{0} \mathrm{Pt}^{I I}$ dioctylether method).

\section{Nanoparticles' preparation by the $F e^{I I} P t^{I I} T E G$ method $^{11}$}

A reaction flask containing a stirred mixture of $\mathrm{Pt}(\mathrm{acac})_{2}(207$ $190 \mathrm{mg} ; 0.53 \mathrm{mmol}), \quad \mathrm{Fe}(\mathrm{acac})_{2} \quad(134 \mathrm{mg} ; 0.53 \quad \mathrm{mmol})$, tetraethylene glycol $(28.5 \mathrm{~g} ; 146.7 \mathrm{mmol})$ and $\mathrm{C}_{12} \mathrm{E}_{8}(576 \mathrm{mg})$ is put into a salt bath at $330^{\circ} \mathrm{C}$. The reaction mixture is kept under reflux for $4 \mathrm{~h} 20$ under argon flow. Then it is cooled down to room temperature and the particles are transferred 195 into the toluene phase. For this phase transfer, oleic acid (158 $\mathrm{mg}$ ) and oleylamine $(150 \mathrm{mg})$ in toluene $(60 \mathrm{~mL})$ are added to the reaction mixture. Stirring with a high-speed mechanical stirrer (23000 rpm for $2 \mathrm{~min}$ ) results in an emulsion, which decants into an orange TEG and a black toluene phase. The 200 toluene phase is concentrated to $20 \mathrm{~mL}$, then oleic acid and oleylamine $(50 \mu \mathrm{L}$ of each) are added. The resulting dispersion is precipitated a first time by adding anhydrous ethanol $(60 \mathrm{~mL})$. Particles are then centrifuged and redispersed in toluene $(20 \mathrm{~mL})$ with stabilising ligands $(50 \mu \mathrm{L}$ 205 of each). After a second precipitation step with $40 \mathrm{~mL}$ of ethanol, followed by centrifugation, the particles are finally dispersed in toluene $(20 \mathrm{~mL})$ containing oleic acid and oleylamine ( $50 \mu \mathrm{L}$ of each).

\section{Characterisation methods}

210 IR absorption spectra were recorded on a FTIR-ATR spectrometer (Perkin Elmer Paragon 500). Proton NMR spectroscopy was performed on a Bruker C200 $\mathrm{MHz}$ spectrometer. X-Ray diffraction of FePt nanoparticles were obtained in the reflection geometry using an X-ray 215 diffractometer (Philips, X'PERT) at room temperature with Co $\mathrm{K} \alpha$ radiation (wavelength $1.789 \AA \AA$ ). FePt nanoparticles were deposited on Silicon wafer substrate by casting and drying the nanoparticles/toluene dispersion. High-resolution TEM micrographs of FePt nanoparticles were obtained using a $220 \mathrm{JEOL} 4000 \mathrm{EX}$ microscope operated at $400 \mathrm{kV}$. For TEM studies, a drop of the diluted FePt dispersion was deposited onto a carbon holey grid (ELOISE SARL). Energy dispersive $\mathrm{x}$-ray spectroscopy measurements were obtained using a scanning electron microscope JEOL JSM-840A. The magnetic ${ }_{225}$ properties of the FePt nanoparticles samples were determined using a Quantum Design DC Superconducting Quantum Interference Device (DC SQUID; Model MPMS XL) magnetometer.

Table 2 Compositions, structural characteristics (diameters determined from TEM images; fcc cell parameter of FePt solid solution) of as-made FePt nanoparticles.

\begin{tabular}{|c|c|c|c|c|c|}
\hline Method & $\begin{array}{l}\text { Av. diameter } \\
\text { (dispersion) }^{a}\end{array}$ & $\begin{array}{c}\text { Precursors } \\
\text { composition }^{b}\end{array}$ & $\begin{array}{c}\text { Global } \\
\text { composition }^{c}\end{array}$ & \begin{tabular}{c|}
$a(\AA)$ \\
Core composition $^{d}$
\end{tabular} & \\
\hline $\begin{array}{c}\mathrm{Fe}^{0} \mathrm{Pt}^{\mathrm{II}} \\
\text { dioctylether }\end{array}$ & $\begin{array}{l}3.4 \mathrm{~nm} \\
(16 \%)\end{array}$ & $\mathrm{Fe}_{67} \mathrm{Pt}_{33}$ & $\mathrm{Fe}_{51} \mathrm{Pt}_{49}$ & \begin{tabular}{l|}
$3.884 \AA$ \\
$\mathrm{Fe}_{32} \mathrm{Pt}_{68}$
\end{tabular} & core-shell structure (Fe shell: $0.18 \mathrm{~nm}$ thick $\approx 1$ layer) \\
\hline $\begin{array}{c}\mathrm{Fe}^{0} \mathrm{Pt}^{\mathrm{II}} \\
\text { dibenzylether }\end{array}$ & $\begin{array}{l}7.4 \mathrm{~nm} \\
(12 \%)\end{array}$ & $\mathrm{Fe}_{67} \mathrm{Pt}_{33}$ & $\mathrm{Fe}_{28} \mathrm{Pt}_{72}$ & $\begin{array}{l}3.889 \AA \\
\mathrm{Fe}_{28} \mathrm{Pt}_{72}\end{array}$ & no shell and global composition is not Fe rich enough \\
\hline $\begin{array}{c}\mathrm{Fe}^{\mathrm{II}} \mathrm{Pt}^{\mathrm{II}} \\
\text { diphenylether }\end{array}$ & $\begin{array}{l}4.2 \mathrm{~nm} \\
(14 \%)\end{array}$ & $\mathrm{Fe}_{60} \mathrm{Pt}_{40}$ & $\mathrm{Fe}_{60} \mathrm{Pt}_{40}$ & $\begin{array}{l}3.887 \AA \\
\mathrm{Fe}_{30} \mathrm{Pt}_{70}\end{array}$ & $\begin{array}{c}\text { core-shell structure (Fe shell: }<0.37 \mathrm{~nm} \text { thick } \approx \text { less } \\
\text { than } 2 \text { layers) }\end{array}$ \\
\hline $\begin{array}{c}\mathrm{Fe}^{-\mathrm{II}} \mathrm{Pt}^{\mathrm{II}} \\
\text { dioctylether }\end{array}$ & $\begin{array}{l}3.4 \mathrm{~nm} \\
(15 \%)\end{array}$ & $\mathrm{Fe}_{50} \mathrm{Pt}_{50}$ & $\mathrm{Fe}_{48} \mathrm{Pt}_{52}$ & $\begin{array}{l}3.885 \AA \\
\mathrm{Fe}_{31} \mathrm{Pt}_{69}\end{array}$ & core-shell structure (Fe shell: $0.15 \mathrm{~nm}$ thick $\approx 1$ layer) \\
\hline $\begin{array}{l}\mathrm{Fe}^{\mathrm{II}} \mathrm{Pt}^{\mathrm{II}} \\
\mathrm{TEG}\end{array}$ & $3.0 \mathrm{~nm}^{e}$ & $\mathrm{Fe}_{50} \mathrm{Pt}_{50}$ & $\mathrm{Fe}_{47} \mathrm{Pt}_{53}$ & $\begin{array}{l}3.851 \AA \\
\mathrm{Fe}_{46} \mathrm{Pt}_{54}\end{array}$ & no shell but global composition is Fe rich enough \\
\hline
\end{tabular}

${ }^{a}$ Diameters determined from TEM images. ${ }^{b}$ Composition given by the molar ratio of metal precursors initially used. ${ }^{c}$ Composition obtained through EDX or ICP-AES. ${ }^{d}$ fcc cell parameter of the FePt alloy and composition derived from Végard's law. ${ }^{12}{ }^{e}$ Diameter of the crystallites determined with Xray diffraction using Scherrer's formula. 


\section{Results and discussion}

\section{${ }_{230}$ FePt nanoparticles’ synthesis}


$\left(103^{\circ} \mathrm{C}\right.$ ), that is far below the reaction temperature (up to $295^{\circ} \mathrm{C}$ ) and therefore the $\mathrm{Fe}$ precursor reacts at the liquidvapour interface within the reaction flask. This virtually 235 reduces the quantity of $\mathrm{Fe}(\mathrm{CO})_{5}$ available at a given reaction time with respect to the initially introduced quantity. In order to compensate for this "loss" and to get an equimolar final composition, an excess of Fe precursor is used as compared to the Pt one (see precursors' composition in Table 2).

240 The analysis of high-resolution TEM micrographs indicates that particles with an average diameter of $3.4 \mathrm{~nm}$ are obtained. XRD reveals that they are made of FePt solid solution. The disordered alloy has a face-centred cubic symmetry, with a cell parameter $a=3.884 \AA$. This value is consistent with a 245 composition $\mathrm{Fe}_{32} \mathrm{Pt}_{68}$, according to Végard's law, which describes the cell parameter value of a substitutional solid solution. ${ }^{12}$ The composition has to be compared with the global composition we deduced from ICP-AES, $\mathrm{Fe}_{51} \mathrm{Pt}_{49}$. The difference between both values is the first indication that 250 suggests a core-shell structure for as-made particles. According to that model, particles are constituted by an irondepleted core ( $32 \%$ atomic) surrounded by a shell made of pure iron. This model is only valid if no iron oxide particles, or any second by-product, is present in the analyzed fraction.

255 Indeed, we neither observed any diffraction peaks corresponding to a second phase, nor any iron oxide particles in TEM micrographs. Such particles can be easily recognized with TEM, by measuring the lattice parameter or using the diffraction mode. They also appear less contrasted than FePt 260 particles on the micrographs, since $\mathrm{Fe}$ has a significantly lower atomic number $Z$ than Pt.

If we suppose that the FePt nanoparticles are spherical, we can calculate an average shell thickness by comparing the global composition and the core composition. The value we 265 obtain, $0.18 \mathrm{~nm}$, corresponds to one $\mathrm{Fe}$ monolayer. This confirms that the X-Ray data are consistent with a core-shell structure: such a thin shell would not give significant XRD contribution. However, it is able to compensate for the irondepletion of the core because at the nanometer scale, a huge 270 number of atoms are located on the surface. For example, a truncated octahedral shaped particle with $3.3 \mathrm{~nm}$ diameter will include a total number of 1289 atoms, among which 502 atoms are located on the surface, i.e. $39 \%$ of the total amount.

1,2-hexadecanediol is considered both as a reducing agent 275 and as a co-surfactant, ${ }^{8}$ since it is an amphiphilic molecule. ${ }^{13}$ We performed a synthesis without 1,2-hexadecanediol and found that $4.0 \mathrm{~nm}$ diameter FePt particles were formed in this way. In this case, the $\mathrm{Pt}^{\mathrm{II}}$ precursor is likely reduced by the $\mathrm{Fe}^{0}$ precursor, which yields metallic platinum, but also 280 oxidised iron in the $\mathrm{Fe}^{\mathrm{II}}$ state. Such a reaction, which can easily be explained by the more noble character of $\mathrm{Pt}$, has already been mentioned by Shukla et al. ${ }^{14}$ A TEM investigation of the particles we prepared without diol is consistent with this hypothesis. We observed a thick iron

285 oxide shell around FePt nanoparticles, as well as some iron oxide particles. The global stoichiometry determined with
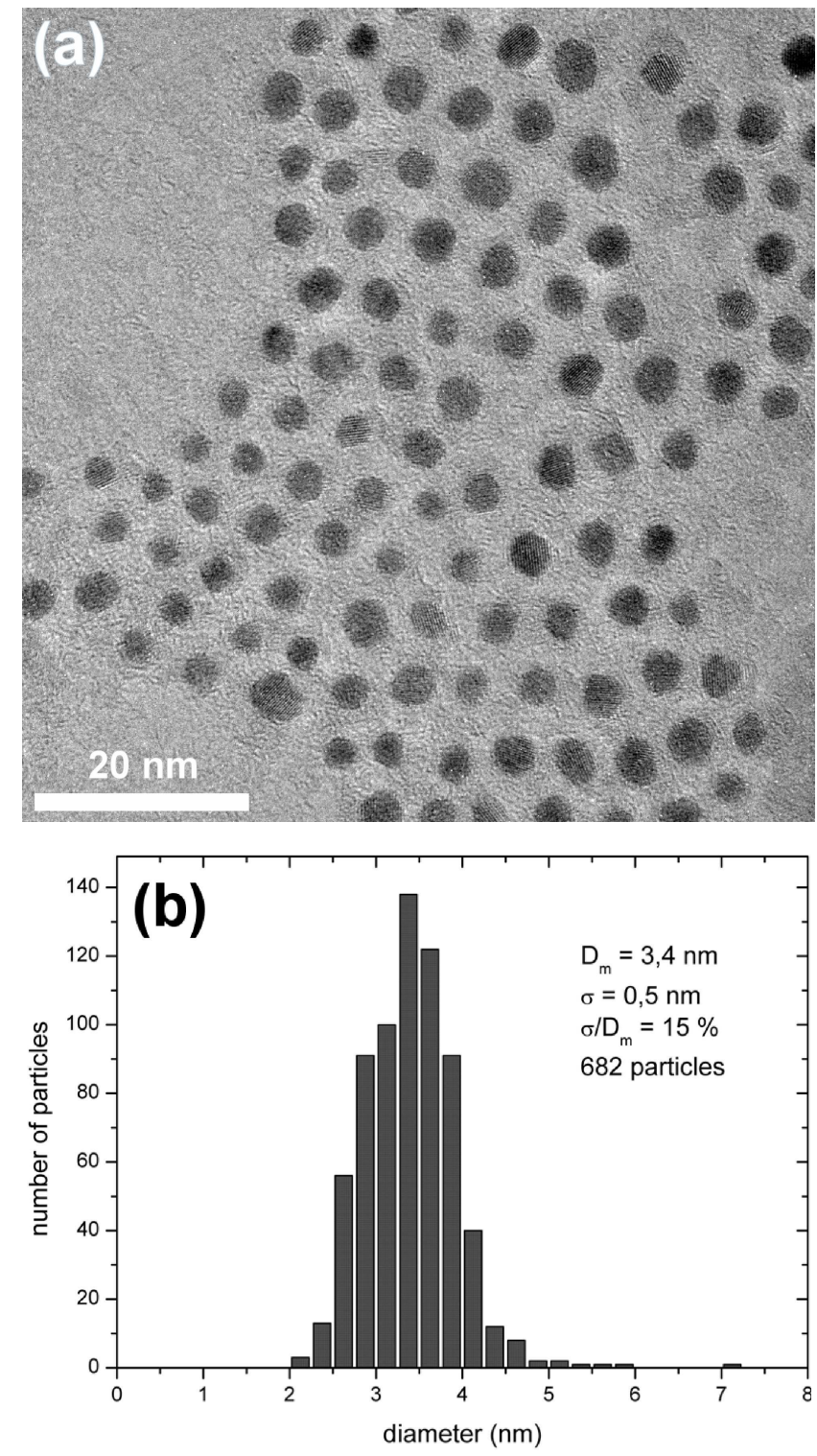

Fig. 1 (a) TEM micrograph of nanoparticles produced by the $F e^{-I I} P t^{I I}$ dioctylether method. (b) Diameter distribution of these particles determined from TEM observations.

EDX is $\mathrm{Fe}_{60} \mathrm{Pt}_{40}$, whereas the core stoichiometry from XRD measurements accounts for $\mathrm{Fe}_{35} \mathrm{Pt}_{65}$. If we assume that all the $\mathrm{Pt}$ atoms are present in $\mathrm{FePt}$ alloy, we deduce that in a particle 290 composed of 100 atoms, $40 \mathrm{Pt}^{0}$ and $21 \mathrm{Fe}^{0}$ atoms are located in core. As a consequence, there are $39 \mathrm{Fe}^{\mathrm{II}}$ atoms left, located in iron oxide shell and separate iron oxide particles. Hence, the amount of metallic Pt is as high as the amount of oxidised Fe. This rough calculation corroborates the assumption that, in 295 absence of 1,2-hexadecanediol, the $\mathrm{Pt}^{\mathrm{II}}$ precursor oxidises the $\mathrm{Fe}^{0}$ precursor.

$\mathrm{Fe}^{0} \quad \mathrm{Pt}^{\mathrm{II}}$ dibenzylether method: In this method, our experimental results suggest that dibenzylether acts simultaneously as the solvent and the reducing agent. We 300 detected the formation of toluene and benzaldehyde during the reaction (cf. Experimental Section). This indicates that the ether bond $\mathrm{C}-\mathrm{O}$ of dibenzylether underwent a homolytic cleavage yielding mesomery-stabilised benzyl and benzoyl radicals, which most probably play a role in the synthesis 
305 reaction. For the elucidation of the detailed mechanism further studies are necessary, which go beyond the scope of the present article.

Like in the previous method: i) an analysis of the global composition by EDX reveals that a significant amount of Fe 310 precursor is lost during the synthesis, ii) XRD results are consistent with an iron-depleted core. Interestingly, we observe that the global composition is the same as the core composition. We infer from this that in this case no Fe shell is present. The exclusion of an additional reducing agent, such 315 as diol or hydride, slows down the nucleation rate and leads to larger particles.

$\mathrm{Fe}^{\mathrm{II}} \mathrm{Pt}^{\mathrm{II}}$ diphenylether method: Since this process uses a non volatile $\mathrm{Fe}$ precursor and a strong reducing agent, no $\mathrm{Fe}$ loss is observed during synthesis. But once again, an iron320 depleted core is formed, which is covered by an iron shell. The calculated shell thickness accounts for 2 layers (see Table 2 ). This value is however probably overestimated due to the presence of a small number of iron oxide nanoparticles visible in TEM micrographs.

$325 \quad \mathrm{Fe}^{-\mathrm{II}} \mathrm{Pt}^{\mathrm{II}}$ dioctylether method: In this process, $\mathrm{Fe}$ precursor is the reducing agent of $\mathrm{Pt}^{\mathrm{II}}$ and the reaction can be written schematically: ${ }^{10} \mathrm{Fe}^{-\mathrm{II}}+\mathrm{Pt}^{\mathrm{II}} \rightarrow \mathrm{Fe}^{0}+\mathrm{Pt}^{0}$. Since the transformation of one $\mathrm{Pt}^{+I I}$ cation to the metallic state requires the presence of one $\mathrm{Fe}^{-\mathrm{II}}$ anion, we expect the formation of 330 homogeneous particles with close to perfect $\mathrm{Fe}_{50} \mathrm{Pt}_{50}$ stoichiometry. Heterogeneous nucleation (nucleation of $\mathrm{Fe}$ without Pt) should also be avoided in such a process.

Surprisingly, the as-made particles prepared by this method (see Figure 1) also show a core-shell structure with an iron335 depleted core, but with a global composition close to $\mathrm{Fe}_{50} \mathrm{Pt}_{50}$.

$\mathrm{Fe}^{\mathrm{II}} \mathrm{Pt}^{\mathrm{II}}$ TEG method: This way of synthesising FePt nanoparticles is attractive since it is very easy to put into practice: there is no need for additional stabilising ligands and reducing agents and no pyrophoric, volatile or toxic $\mathrm{Fe}$ 340 precursor is required. Furthermore, it is likely to provide partially ordered particles because of slower growth kinetics. ${ }^{15}$ A major disadvantage of the polyol process is however that it yields highly polydispersed and strongly aggregated particles. We performed a phase transfer from TEG to toluene through 345 an emulsion step, but still the particles were poorly soluble. We also tried polyol reactions in TEG with stabilising ligands, either with $\mathrm{C}_{12} \mathrm{E}_{8}$ (octaethylene glycol monododecylether) or with oleic acid and oleylamine mixed with $\mathrm{C}_{12} \mathrm{E}_{8}$. But none of these experiments provided well-dispersed nanoparticles.

350 Like in the other method using a cationic $\mathrm{Fe}^{\mathrm{II}}$ precursor, no Fe loss occurs: the precursors' composition and the global composition are similar. Furthermore, the lattice parameter is significantly lower than in all the other methods. As a result, we do not observe a core-shell structure and particle 355 composition is close to $\mathrm{Fe}_{50} \mathrm{Pt}_{50}$.

\section{Magnetic properties (as-grown nanoparticles)}

Magnetic measurements provide further insight on the asgrown FePt nanoparticles, with new data that have to be compared with chemical and structural ones to assess the 360 consistency of the analysis here provided.

Let us start with the magnetic anisotropy. This key parameter for any application can be derived from the
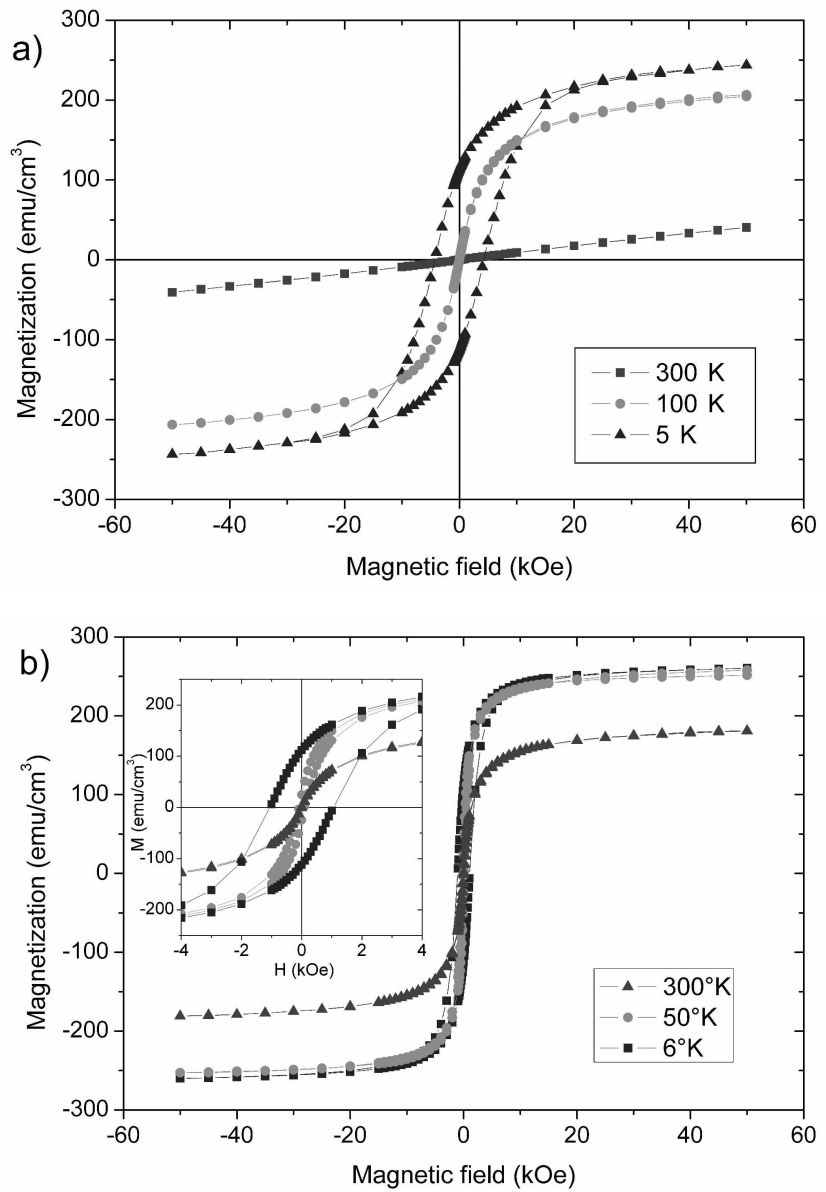

Fig. 2 Magnetic hysteresis loops of FePt nanoparticles prepared with (a) the $F e^{0} P t^{I I}$ dioctylether method, and with (b) the $F e^{I I} P t^{I I} T E G$ method. The inset restricts to the low field values.

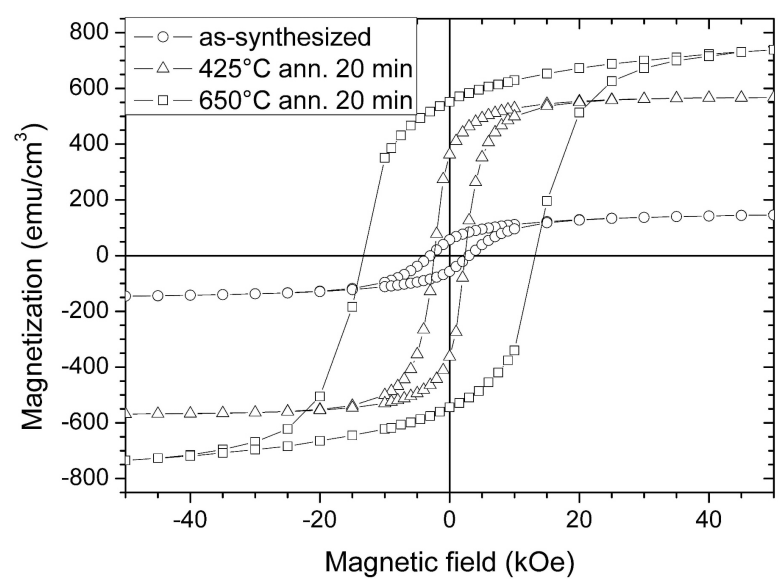

Fig. 3 A series of low-temperature $(T=6 \mathrm{~K})$ magnetisation measurement for various annealing temperatures for particles made with the $\mathrm{Fe}^{0} \mathrm{Pt}^{\mathrm{II}}$ dioctylether method.

$$
\mathrm{K}_{\mathrm{u}} \cdot \mathrm{V}=\mathrm{k}_{\mathrm{B}} \cdot \mathrm{T}_{\mathrm{B}} \cdot \ln \left(\mathrm{f}_{0} \cdot \mathrm{t}_{\mathrm{m}}\right)
$$






Fig. 4 Magnetisation as a function of temperature for FePt nanoparticles obtained by three chemical synthesis methods.

blocking temperature $\left(\mathrm{T}_{\mathrm{B}}\right)$. Above $\mathrm{T}_{\mathrm{B}}$, even if the local ferromagnetic alignment of the individual spins is preserved,

365 the magnetic moment of each nanoparticle is randomly reversed by thermal fluctuations. One can write Equation (1) for non-interacting magnetic nanoparticles, where $\mathrm{k}_{\mathrm{B}}$ stands for the Boltzmann constant, $\mathrm{K}_{\mathrm{u}}$ and $\mathrm{V}$ for the magnetic anisotropy and the volume of the nanoparticle respectively. $\mathrm{f}_{0}$ 370 is the attempt frequency, classically taken as $10^{9} \mathrm{~Hz}, \mathrm{t}_{\mathrm{m}}$ the mean time elapsed between thermally induced reversal events. Here, $T_{B}$ values are extracted using a classical procedure from the Field Cooled - Zero Field Cooled (FC-ZFC) magnetisation curves obtained with a SQUID magnetometer

375 (Table 3). These values of $T_{B}$ correspond to a magnetic anisotropy in the $10^{5} \mathrm{~J} / \mathrm{m}^{3}$ range. Some uncertainty arises from the fact that the mere application of Equation (1) does not take into account the size and anisotropy dispersions of the FePt nanoparticles. However, this uncertainty does not hide the key 380 result: as-grown nanoparticles exhibit anisotropy values roughly one order of magnitude lower than the ones that would be associated to the chemically ordered phase. This result is consistent with the X-Ray data indicating that the asgrown nanoparticles are within the chemically disordered fcc 385 phase.

In addition, we found very low magnetisation values for all as-synthesised $\mathrm{FePt}$ nanoparticles, relative to the $\mathrm{Fe}_{50} \mathrm{Pt}_{50}$ bulk values (1140 emu/cm $\mathrm{cm}^{3}$ for the $\mathrm{L}_{0}$ phase) (Table 3). Interestingly, such a low magnetisation (with respect to the

Table 3 Magnetic properties of as-synthesised nanoparticles

\begin{tabular}{|c|c|c|c|}
\cline { 2 - 4 } \multicolumn{1}{c|}{} & $\begin{array}{c}\mathrm{Fe}^{0} \mathrm{Pt}^{\mathrm{II}} \\
\text { dioctylether }\end{array}$ & $\begin{array}{c}\mathrm{Fe}^{-\mathrm{II}} \mathrm{Pt}^{\mathrm{II}} \\
\text { dioctylether }\end{array}$ & $\begin{array}{c}\mathrm{Fe}^{\mathrm{II}} \mathrm{Pt}^{\mathrm{II}} \\
\mathrm{TEG}\end{array}$ \\
\hline $\begin{array}{c}\mathrm{T}_{\mathrm{B}}(\mathrm{K})^{a} \\
\mathrm{H}=100 \mathrm{Oe}\end{array}$ & 20 & 14 & 85 \\
\hline $\begin{array}{c}\mathrm{M}_{\mathrm{s}}(6 \mathrm{~K}) \\
\left(\mathrm{emu} / \mathrm{cm}^{3}\right)\end{array}$ & 244 & 185 & 310 \\
\hline $\begin{array}{c}\text { Coercive field } \mathrm{H}_{\mathrm{c}} \\
(\text { Oe })\end{array}$ & 4200 & 1600 & 1000 \\
\hline $\begin{array}{c}\text { Curie temperature } \\
(\mathrm{K})\end{array}$ & 260 & 1.36 & 600 \\
\hline$\alpha$ exponent & 1.74 & \multicolumn{2}{c|}{} \\
\hline
\end{tabular}

${ }^{a} t_{\mathrm{m}}$ value fixed at $100 \mathrm{~s}$, the acquisition time of an experimental point for the FC-ZFC curves.
390 bulk value) has been observed for chemically grown $\mathrm{NiFe}_{2} \mathrm{O}_{4}$ nanoparticles coated with surfactants like oleic acid. ${ }^{16}$ The authors proposed that the strong interaction between the surfactants and the surface of the nanoparticle may result in a non-ferromagnetic shell. The same idea has been recently 395 proposed for FePt nanoparticles coated with oleic acid. ${ }^{17}$ Within a $3.5 \mathrm{~nm}$ diameter nanoparticle, $40 \%$ of the atoms are at the surface. Hence, a pure iron shell (whose existence is suggested by structural data) would mean that $80 \%$ of iron atoms included within a $\mathrm{Fe}_{50} \mathrm{Pt}_{50}$ nanoparticle are at the 400 surface. If non magnetic, such an Fe shell will then reduce the average magnetisation down to the experimental values. Furthermore, the magnetisation appears higher for the nanoparticles prepared using the $F e^{I I} P t^{I I} T E G$ method. This is perfectly consistent with the absence of a core-shell structure 405 in this latter case, as deduced from the structural data. Once again, a rough quantitative estimation fits well with the measured magnetisation.

The hysteresis loops provide other interesting pieces of information. For the nanoparticles prepared in dioctylether by 410 the $F e^{0} P t^{I I}$ method: At $5 \mathrm{~K}$, below the blocking temperature, it is interesting to see that we do not get the square loop that would be expected from a Stoner Wolfarth model (reversal by coherent rotation of the magnetisation axis). ${ }^{18}$ This is likely due to a dispersion in the anisotropy values of the 415 nanoparticles, that lead to a corresponding dispersion of the coercive fields. More detailed simulations indicate that a value of 0.6 for standard deviation (lognormal distribution) of the anisotropy value is required to correctly fit the experimental curve. At $100 \mathrm{~K}$, the hysteresis loop follows 420 quite well the Langevin law describing the evolution of the magnetisation against the field of an assembly of identical and non-interacting magnetic particles at high temperature $\left(T>T_{B}\right.$

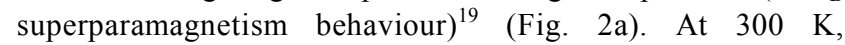
whereas the magnetisation of nanoparticles produced by $T E G$ 425 method follows a Langevin law (Fig. 2b), a linear variation is observed for the ones prepared by $F e^{0} P t^{I I}$ dioctylether method. Such a linear variation, expected for paramagnetic materials, indicates that the measurement temperature is above or not far from the Curie temperature. More directly, 430 the Curie temperature can be deduced by fitting the $\mathrm{M}(\mathrm{T})$ curves obtained under a large applied field (Fig. 3). The law in Equation 2 is derived from the spin wave model that stands far below the Curie temperature. The exponent $\alpha$ generally takes the value $3 / 2$ (Block law) for bulk ferromagnetic 435 materials. For both dioctylether based synthesis (Table 3), we obtain reasonable values for $\alpha$, and Curie temperatures far below the ones expected at the equiatomic composition (750 $\mathrm{K}$ for the $\mathrm{L} 1_{0}$ phase, $\sim 600 \mathrm{~K}$ for the fcc phase). According to the published phase diagram of the FePt alloy, ${ }^{20}$ a Curie 440 temperature in the $300 \mathrm{~K}$ range would correspond to a $\mathrm{Fe}_{30} \mathrm{Pt}_{70}$ composition (close to the composition values of the nanoparticles cores deduced from XRD data, see Table 2). Conversely, the Curie temperature is clearly far higher for the nanoparticles prepared by the TEG method (Fig. 3). This is 445 consistent with an iron richer composition of the nanoparticle

$$
\mathrm{M}=\mathrm{M}_{\mathrm{n}}\left(1-\mathrm{BT}^{\alpha}\right)
$$


core, as expected in the absence of a core-shell structure.

\section{XPS study}

An XPS study (see Figure 5a and Table 4) reveals that asmade particles include only one type of $\mathrm{Pt}$ atoms. Pt $4 \mathrm{f} 7 / 2$ 450 binding energy corresponds to $\mathrm{Pt}^{0}$. Similarly, only one kind of $\mathrm{Fe}$ atom can be observed (see Figure 5 b), and $\mathrm{Fe} 2 \mathrm{p} 3 / 2$ binding energy corresponds to $\mathrm{Fe}^{\mathrm{III}}$. These oxidised $\mathrm{Fe}$ atoms are those from the iron outer shell, and their oxidation state explains why they are non magnetic.

455 In order to probe the core of particles, we conducted $\mathrm{Ar}$ sputtering experiments. As shown by Table 4, the molar ratio $\mathrm{Fe} / \mathrm{Pt}$ decreases after Ar sputtering, which indicates that more $\mathrm{Fe}$ atoms were etched than $\mathrm{Pt}$ atoms. Then, two types of $\mathrm{Fe}$ atoms are detected after etching: $\mathrm{Fe}^{0}$ from core $(38 \%)$ and ${ }_{460} \mathrm{Fe}^{\mathrm{III}}$ from shell $(62 \%)$. It is in accordance with a core-shell structure including a core made of $\mathrm{Pt}^{0}$ and $\mathrm{Fe}^{0}$, and a shell only made of $\mathrm{Fe}^{\mathrm{III}}$. That is the reason why we still observe only one kind of $\mathrm{Pt}$ atoms after etching, corresponding to $\mathrm{Pt}^{0}$ from core. Non-oxidised $\mathrm{Fe}$ atoms from core cannot be seen 465 without etching because the probe depth with the XPS technique is not large enough.

As a conclusion, both magnetic properties and XPS studies indicate a core-shell structure for as-made FePt nanoparticles prepared by the three following methods: $\mathrm{Fe}^{0} \mathrm{Pt} t^{I I}$ dioctylether, ${ }_{470} \mathrm{Fe}^{I I} \mathrm{Pt}{ }^{I I}$ diphenylether and $\mathrm{Fe}^{-I I} P t^{I I}$ dioctylether. The shell is likely to consist of iron oxide (non magnetic iron in the $\mathrm{Fe}^{\mathrm{III}}$ state) and is too thin to be seen on TEM micrographs and to generate a significant XRD signal. Such a non magnetic shell has already been mentioned in literature and was called dead 475 layer: $\mathrm{Wu}$ et al attributed the low magnetisation state of this layer to bonds between carbonyl groups of oleic acid and $\mathrm{Fe}^{21}$ Anders et al carried out a NEXAFS study on FePt nanoparticles and showed that a very thin layer of oxide $(0.4$ $\mathrm{nm}$ ) surrounding particles is sufficient to explain the observed 480 spectra. $^{22}$ Finally, a Mössbauer study by Stahl et al. indicates two types of $\mathrm{Fe}$ atoms in as-made $\mathrm{FePt}$ nanoparticles prepared with $\mathrm{Fe}^{0} \mathrm{Pt}^{I I}$ dioctylether method. ${ }^{23}$

Now let us focus on the availability of the Fe atoms of the shell: are they able to take part in the building of the ordered ${ }_{485}$ phase? If it is not, core-shell particles will remain irondepleted after chemical ordering. Conversely, if $\mathrm{Fe}$ atoms from the shell can diffuse into core, the transition phase of particles will lead to the equimolar ordered phase $\mathrm{L}_{0}$. This is obviously a key point for the targeted application of $\mathrm{FePt}$ 490 nanoparticles in data storage.

\section{Annealing experiments}

The diagram phase of FePt alloy indicates that for

Table 4 Argon etching experiment on nanoparticles prepared with the $\mathrm{Fe}^{0}$ $P t^{I I}$ dioctylether method. These experiments were monitored with X-Ray Photoelectron Spectroscopy.

\begin{tabular}{|c|c|c|}
\cline { 2 - 3 } \multicolumn{1}{c|}{} & before Ar sputtering & after Ar sputtering \\
\hline molar ratio Fe/Pt & 1.04 & 0.63 \\
\hline binding energy (eV) Pt 4f 7/2 & 71.3 & 71.4 \\
\hline \multirow{2}{*}{ binding energy (eV) Fe 2p 3/2 } & $710.8(100 \%)$ & $707.4(38 \%)$ \\
& & $709.7(62 \%)$ \\
\hline
\end{tabular}

${ }^{a}$ Ar with $3 \mathrm{keV}$ energy, $10^{-6} \mathrm{mbar}, 15 \mathrm{~min}$. compositions between $\mathrm{Fe}_{44} \mathrm{Pt}_{56}$ and $\mathrm{Fe}_{62} \mathrm{Pt}_{38}$, chemical ordering will lead to $\mathrm{L} 1_{0}$ phase. On the other hand, particles 495 with iron-depleted compositions ranging from $\mathrm{Fe}_{20} \mathrm{Pt}_{80}$ to $\mathrm{Fe}_{40} \mathrm{Pt}_{60}$ will generate $\mathrm{L} 1_{2}$ ordered phase showing one $\mathrm{Fe}$ atom for three $\mathrm{Pt}$ atoms. As a consequence, if $\mathrm{Fe}$ atoms from shell are not available, a core-shell FePt nanoparticle will yield a particle made of $\mathrm{L}_{2}$ phase core, covered with an iron oxide
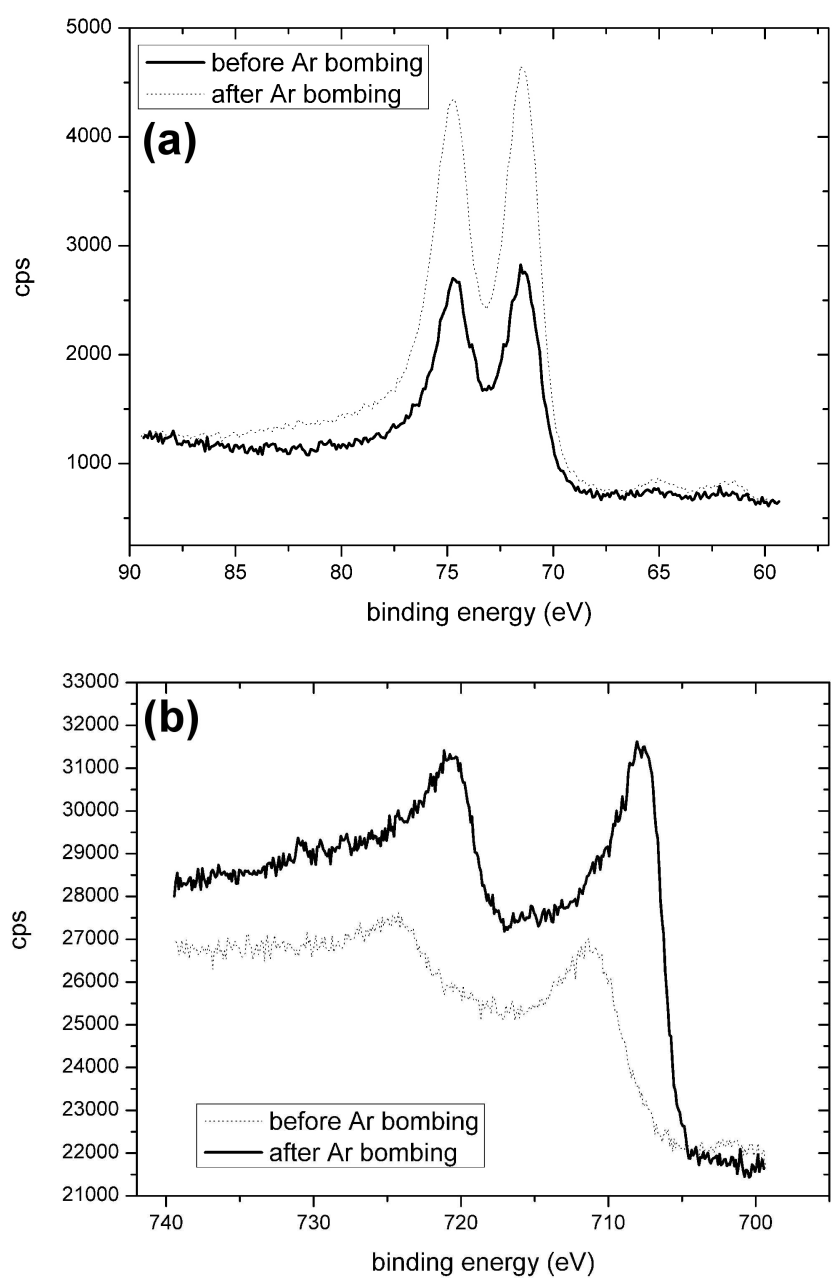

Fig. 5 X-Ray photoelectron spectroscopy of nanoparticles prepared with the $\mathrm{Fe}^{0} \mathrm{Pt}$ dioctylether method. (a) $\mathrm{Pt} 4 \mathrm{f} 7 / 2$ peaks of particles before and after Ar sputtering. (b) Fe 2p 3/2 peaks of particles before and after Ar sputtering.

Table 5 Chemically ordered phases obtained after annealing the nanoparticles $\left(650^{\circ} \mathrm{C}, 1 \mathrm{~h}\right.$, under vacuum) deposited on $\mathrm{SiO}_{2}$ substrates.

\begin{tabular}{|c|c|c|}
\hline Process & Global composition & $\begin{array}{c}\text { Ordered phase } \\
\text { Cell parameters }(\AA)\end{array}$ \\
\hline $\begin{array}{c}\mathrm{Fe}^{0} \mathrm{Pt}^{\mathrm{II}} \\
\text { dioctylether }\end{array}$ & $\mathrm{Fe}_{51} \mathrm{Pt}_{49}$ & $\begin{array}{c}\mathrm{L} 1_{0} \\
a=3.859 ; c=3.736\end{array}$ \\
\hline $\begin{array}{c}\mathrm{Fe}^{0} \mathrm{Pt}^{\mathrm{II}} \\
\text { dibenzylether }\end{array}$ & $\mathrm{Fe}_{28} \mathrm{Pt}_{72}$ & $\begin{array}{c}\text { Disordered } \mathrm{FePt}+\mathrm{L}_{2} \\
a=3.868\end{array}$ \\
\hline $\begin{array}{c}\mathrm{Fe}^{\mathrm{II}} \mathrm{Pt}^{\mathrm{II}} \\
\text { diphenylether }\end{array}$ & $\mathrm{Fe}_{60} \mathrm{Pt}_{40}$ & $\begin{array}{c}\mathrm{L} 1_{0} \\
a=3.839 ; c=3.711\end{array}$ \\
\hline $\begin{array}{c}\mathrm{Fe}^{-\mathrm{II}} \mathrm{Pt}^{\mathrm{II}} \\
\text { dioctylether }\end{array}$ & $\mathrm{Fe}_{48} \mathrm{Pt}_{52}$ & $\begin{array}{c}\mathrm{L1}_{0} \\
a=3.862 ; c=3.726\end{array}$ \\
\hline $\begin{array}{l}\mathrm{Fe}^{\mathrm{II}} \mathrm{Pt}^{\mathrm{II}} \\
\mathrm{TEG}\end{array}$ & $\mathrm{Fe}_{47} \mathrm{Pt}_{53}$ & $\begin{array}{c}\mathrm{L} 1_{0} \\
a=3.859 ; c=3.737\end{array}$ \\
\hline
\end{tabular}

${ }^{a} \mathrm{L1}_{0}$ phase is face centred tetragonal, $\mathrm{L1}_{2}$ phase is face centred cubic.

This journal is (c) The Royal Society of Chemistry [year]

8 | J. Mater. Chem., 2006, [vol], 00-00 

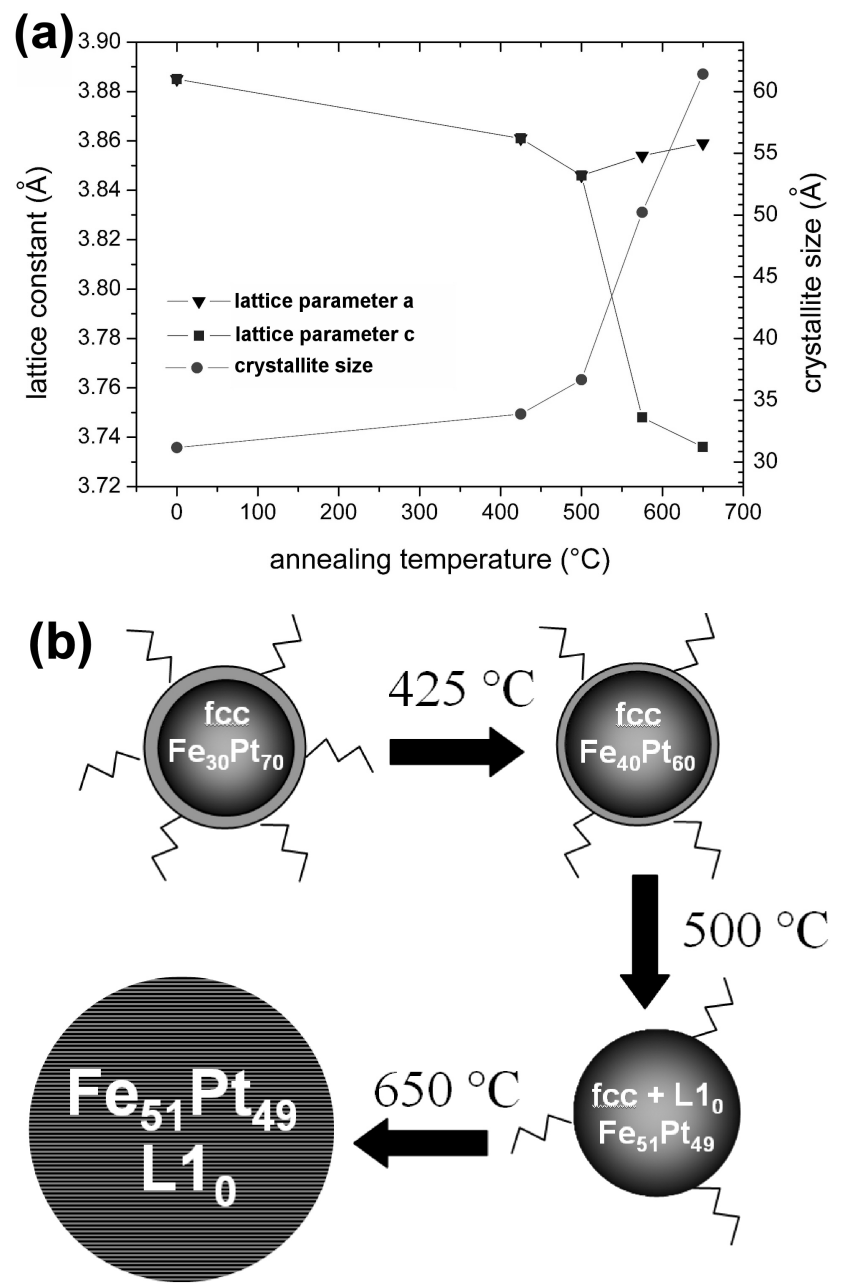

Fig. 6 (a) These curves plot lattice constants $(a$ and $c$ ) and crystallite size versus temperature for FePt nanoparticles annealed 2 hours under vacuum (particles made with the $F e^{0} P t^{I I}$ dioctylether method). (b) This scheme represents the diffusion of $\mathrm{Fe}$ atoms from shell into core, so as to take part into the building of $\mathrm{L}_{0}$ phase. The compositions indicated on particles are core compositions deduced from lattice constant.

500 shell.

Table 5 gathers results for the annealing processes of all particles, which consisted in a heating treatment under vacuum $\left(10^{-5}\right.$ to $\left.10^{-6} \mathrm{mbar}\right)$. All the particles having a global composition between $\mathrm{Fe}_{47} \mathrm{Pt}_{53}$ and $\mathrm{Fe}_{60} \mathrm{Pt}_{40}$ produced $\mathrm{L}_{0}$ 505 phase, thereby proving the ability for $\mathrm{Fe}$ atoms from shell to diffuse. As expected, particles prepared with $\mathrm{Fe}^{0} \mathrm{Pt}^{I I}$ dibenzylether method yielded $\mathrm{L}_{2}$ phase. They have indeed an iron-depleted global composition.

We monitored the transition phase by means of XRD, as 510 shown in Figure 6a, for particles synthesised with $\mathrm{Fe}^{0} \mathrm{Pt}^{I I}$ dioctylether method. The transition phase between disordered fcc solid solution and ordered fct phase $\mathrm{L}_{0}$ occurs when lattice constant $a$ splits into $a$ and $c$ parameters, i.e. at about $500^{\circ} \mathrm{C}$. Interestingly, we notice a downward trend of the 515 lattice constant $a$ before splitting. The same tendency has also been reported recently by Nakaya et al. ${ }^{24}$ but no explanation was given. We think that below $500^{\circ} \mathrm{C}$ the diffusion of $\mathrm{Fe}$ atoms from the shell into the core causes an iron enrichment of the disordered solid solution (see Figure 6b). Since Fe 520 atoms are smaller than $\mathrm{Pt}$ atoms, this enrichment leads to a lower value of the lattice constant $a$. Around $500^{\circ} \mathrm{C}$, the phase transition occurs but sintering cannot be avoided, the crystallite size then strongly increases.

The fact that $\mathrm{Fe}$ atoms would diffuse - at a moderate 525 temperature $(425 \mathrm{~K})$ - from the outer shell towards the alloyed core of the nanoparticles finds further support from the magnetic experiments. Indeed, after a $20 \mathrm{~min}$. annealing at $425^{\circ} \mathrm{C}$, we observe a large increase of $\mathrm{M}_{\mathrm{s}}$. Interestingly, the absence of a significant increase of the coercive field suggests

530 that the anisotropy of the nanoparticles does not strongly increase in the same time (fig. 6). Quantitatively, the increase on the overall magnetisation may be partly induced by the thermal decomposition of the surfactants present at the nanoparticles' surface ${ }^{17}$ (the surfactants being suspected to 535 render the shell non magnetic), in addition to the Fe diffusion within the core. After annealing at a higher temperature $\left(650^{\circ} \mathrm{C}\right.$ ), the coercivity $\mathrm{H}_{\mathrm{c}}$ increases from $4200 \mathrm{Oe}$ (as-grown nanoparticles) to $13 \mathrm{kOe}$. This is consistent with the obtention of the large anisotropy - $\mathrm{L1}_{0}$ phase.

540 In summary, the structural and magnetic studies as well as the annealing experiments support the model of a core-shell structure of the as-prepared FePt nanoparticles. The formation of this structure can be explained by the difference of kinetics between the two following reactions: the reduction of $\mathrm{Pt}^{\mathrm{II}}$ to ${ }_{545} \mathrm{Pt}^{0}$, and the transformation of the Fe precursor into metallic Fe. The nucleation of $\mathrm{Pt}$ is much easier to trigger, that is why the formation of FePt nanoparticles occurs via a Pt-rich core, followed by a slower deposition of Fe and Pt atoms. This twostep growth mechanism has been recently reported in 550 literature for both methods relying on the reduction of $\mathrm{Pt}(\mathrm{acac})_{2}$ and decomposition of $\mathrm{Fe}(\mathrm{CO})_{5}{ }^{9}$ and a process involving the pyrolysis of $\mathrm{Fe}(\mathrm{OEt})_{3}$ and $\mathrm{Pt}(\mathrm{acac})_{2} \cdot{ }^{25}$ Interestingly, we notice that this difference of kinetics leads to a core composition around $\mathrm{Fe}_{30} \mathrm{Pt}_{70}$ (see Table 2), whatever 555 hot soap method is used, i.e. the core compositions of the particles are similar although the chemical mechanisms involved in these four syntheses are completely different. The polyol process TEG is the only preparation method among those studied which does not follow this two-step growth 560 mechanism.

In the case of rather small particles $(4 \mathrm{~nm}$ diameter and

Table 6 Syntheses of larger FePt nanoparticles: structural data about as-made particles and ordered phase obtained from annealing.

\begin{tabular}{|c|c|c|c|c|c|c|}
\hline Process & $\begin{array}{c}\text { Surfactant } \\
\text { (equivalents) }\end{array}$ & Av. diameter (nm) & $\begin{array}{c}\text { Precursors } \\
\text { composition }\end{array}$ & $\begin{array}{c}\text { Global } \\
\text { composition }\end{array}$ & $\begin{array}{c}a(\AA) \\
\text { Core composition }\end{array}$ & $\begin{array}{c}\text { Ordered phase } \\
\text { Lattice parameters }(\AA)\end{array}$ \\
\hline $\begin{array}{c}\mathrm{Fe}^{0} \mathrm{Pt}^{\mathrm{II}} \\
\text { dioctylether }\end{array}$ & 1.5 & $3.4(16 \%)$ & $\mathrm{Fe}_{67} \mathrm{Pt}_{33}$ & $\mathrm{Fe}_{51} \mathrm{Pt}_{49}$ & $3.884\left(\mathrm{Fe}_{32} \mathrm{Pt}_{68}\right)$ & $\mathrm{L}_{0}(a=3.859 ; c=3.736)$ \\
\cline { 2 - 7 } $\begin{array}{c}\mathrm{Fe}^{-\mathrm{II}} \mathrm{Pt}^{\mathrm{II}} \\
\text { dioctylether }\end{array}$ & 8 & $5.0(7 \%)$ & $\mathrm{Fe}_{67} \mathrm{Pt}_{33}$ & $\mathrm{Fe}_{39} \mathrm{Pt}_{61}$ & $3.893\left(\mathrm{Fe}_{26} \mathrm{Pt}_{74}\right)$ & $\mathrm{L} 1_{2}(a=3.867)$ \\
\cline { 2 - 7 } & 8 & $3.4(15 \%)$ & $\mathrm{Fe}_{50} \mathrm{Pt}_{50}$ & $\mathrm{Fe}_{48} \mathrm{Pt}_{52}$ & $3.885\left(\mathrm{Fe}_{31} \mathrm{Pt}_{69}\right)$ & $\mathrm{L}_{0}(a=3.862 ; c=3.726)$ \\
\hline
\end{tabular}

${ }^{a}$ Number of equivalents of oleic acid (compared to the amount of Pt precursor) $=$ number of equivalents of oleylamine. 
less), the iron surface can compensate the iron-depletion of the core, so that the global composition is close to equimolar. Since the surface iron is available during subsequent 565 annealing, the core-shell structure does not hinder the formation of the $\mathrm{L} 1_{0}$ phase. With the goal to verify if this is true also for bigger particles, we carried out syntheses with higher amounts of the stabilising ligands (Table 6), leading to lower nucleation rates and larger particle diameters. EDX and

$570 \mathrm{X}$-ray analyses reveal that the as-made particles also exhibit a core-shell structure, with an iron-depleted core and a shell made of iron. Compared to smaller particles, large diameter samples have a larger core and approximately the same shell thickness, therefore they have an iron-depleted global 575 composition. That is the reason why they yield the $\mathrm{L}_{2}$ ordered phase after annealing and not the $\mathrm{L} 1_{0}$ one.

\section{Conclusions}

We conducted a comparative study on FePt nanoparticles prepared in solution with five different chemical methods. We 580 evidenced by X-ray diffraction and EDX analysis that four of them yielded particles with a core-shell structure consisting of a Pt rich core and a 1-2 monolayers thick Fe shell. The formation of the core/shell structure has its origin in the difference between the nucleation kinetics of $\mathrm{Pt}$ and Fe: $\mathrm{Pt}$ is 585 much easier to nucleate and faster to deposit on the seeds. Our study is the first one to stress that all the hot soap methods provide particles having very similar core compositions (close to $30 \%$ at. $\mathrm{Fe}$ ), though very different chemical reactions are involved in these syntheses. Noteworthy even the method 590 relying on the reduction of $\mathrm{Pt}^{\mathrm{II}}$ by $\mathrm{Fe}^{-\mathrm{II}}$ did not provide homogeneous particles.

We evidenced however that the iron atoms of the shell are available for the formation of the $\mathrm{L} 1_{0}$ phase in the case of small nanoparticles with equimolar global composition. On

595 the contrary, bigger particles yield the $\mathrm{L}_{2}$ phase upon annealing.

A completely different synthesis reaction, of the polyol process, exhibits some distinct differences from the hot soap methods: it yields homogeneous particles having an equimolar 600 global composition. Serious drawbacks of this method are however the small size, the high polydispersity and the poor dispersibility of the formed particles.

A common feature of all hot soap methods is that they use oleylamine as stabilising ligands for $\mathrm{Pt}$ atoms and oleic acid 605 as ligands for $\mathrm{Fe}$. The amount of oleylamine in the initial reaction mixture controls the nucleation of $\mathrm{Pt}$, likewise oleic acid controls the nucleation of Fe. With the goal to synthesise bigger equimolar FePt nanoparticles and to overcome the problem of core-shell structure formation, novel combinations 610 of ligands should be investigated in further studies, reducing the difference of the reaction kinetics of the two metal precursors. Furthermore, the control over the interaction between the surfactant and the metal precursor is one of the key issues for the synthesis of new particle shapes. ${ }^{26}$

615 Reactions involving new ligand molecules such as polyamines, nitriles or thiols are currently under investigation in our laboratory. In order to strengthen the interaction between $\mathrm{Pt}$ and its associated ligand, we are currently investigating syntheses in which oleylamine is replaced by 620 other ligands (such as polyamine, nitrile or thiol).

\section{Acknowledgements}

We are indebted to Dr Pierre Delichère for his very helpful XPS experiments. Assistance by $\mathrm{Dr}$ Pascale BayleGuillemaud for TEM experiments and by Dr Isabelle Schuster ${ }_{625}$ for X-ray diffraction analyses is gratefully acknowledged. This work was supported by French Research National Agency (ANR project CAMAIEU).

\section{Notes and references}

1 (a) T. Hyeon, Chem. Commun., 2003, 927-934 (b) B. L. Cushing, V. L. Kolesnichenko and C. J. O'Connor, Chem. Rev., 2004, 104, $3893-$ 3946 (c) C. Desvaux, C. Amiens, P. Fejes, P. Renaud, M. Respaud, P. Lecante, E. Snoeck and B. Chaudret, Nat. Mater., 2005, 4, 750-753. (d) S. Sun, Adv. Mater., 2006, 18, 393-403 (e) D. L. Huber, Small, 2005, 1, 482-501.

2 (a) H. Kodama, S. Momose, N. Ihara, T. Uzamaki and A. Tanaka, Appl. Phys. Lett., 2003, 83, 5253-5255 (b) S. B. Darling, N. A. Yufa, A. L. Cisse, S. D. Bader and S. J. Sibener, Adv. Mater., 2005, 17, 24462450 (c) S. B. Darling and S. D. Bader, J. Mater. Chem., 2005, 15, 4189-4195 (d) Q. Guo, X. Teng, and H. Yang, Adv. Mater., 2004, 16, 1337-1341.

3 H. Kodama, S. Momose, T. Sugimoto, T. Uzumaki and A. Tanaka, IEEE Trans. Magn., 2005, 41, 665-669.

4 (a) Q. A. Pankhurst, J. Connolly, S. K. Jones and J. Dobson, J. Phys. D: Appl. Phys., 2003, 36, R167-R181 (b) X. Gao, K. Tam, K. M. Kerry Yu and S. C. Tsang, Small, 2005, 1, 949-952.

5 S. Sun, C. B. Murray, D. Weller, L. Folks and A. Moser, Science, 2000, 287, 1989-1992.

6 E. V. Shevchenko, D. V. Talapin, A. L. Rogach, A. Kornowski, M. Haase and H. Weller, J. Am. Chem. Soc., 2002, 124, 11480-11485.

7 S. S. Kang, D. E. Nikles and J. W. Harrell, J. Appl. Phys., 2003, 93, 7178-7180.

8 S. Sun, Us. Pat., 6676 729, 13 january 2004.

9 M. Chen, J. P. Liu and S. Sun, J. Am. Chem. Soc., 2004, 126, 83948395.

10 L. E. M. Howard, H. Loc Nguyen, S. R. Giblin, B. K. Tanner, I. Terry, A. K. Hughes and J. S. O. Evans, J. Am. Chem. Soc., 2005, 127, 10140-10141.

11 B. Jeyadevan, K. Urakawa, A. Hobo, N. Chinnasamy, K. Shinoda, K. Tohji, D. D. J. Djayaprawira, M. Tsunoda and M. Takahashi, Jpn. J. Appl. Phys., 2003, 42, L350.

12 A. Bonakdarpour, J. Wenzel, D. A. Stevens, S. Sheng, T. L. Monchesky, R. Löbel, R. T. Atanasoski, A. K. Schmoeckel, G. D. Vernstrom, M. K. Debe and J. R. Dahn, J. Electrochem. Soc., 2005, 152, A61-A72.

13 G. Weidemann, G. Brezesinski, D. Vollhardt, C. DeWolf and H. Möhwald, Langmuir, 1999, 15, 2901-2910.

14 N. Shukla, C. Liu and A. G. Roy, Mater. Lett., 2006, 60, 995-998.

15 B. Jeyadevan, A. Hobo, K. Urakawa, C. N. Chinnasamy, K. Shinoda and K. Tohji, J. Appl. Phys., 2002, 93, 7574-7576.

16 A. E. Berkowitz, J. A. Lahut, I. S. Jacobs, and Lionel M. Levinson, Phys. Rev. Lett., 1975, 34, 594-597

17 X. W. Wu, C. Liu, L. Li, P. Jones, R. W. Chantrell, and D. Weller, J. Appl. Phys., 2004, 95, 6810-6812.

18 E. C. Stoner and E. P. Wohlfarth, Phil. Trans. Roy. Soc., 1948, A240, 599-642

19 C. P. Bean and J. D. Livingston, J. Appl. Phys., 30 Suppl., 120S-129S.

20 A. Kussman and G. V. Rittberg, Z. Metallk. Metallforsch., 1950, 41, 470

21 X. W. Wu, C. Liu, L. Li, P. Jones, R. W. Chantrell and D. Weller, J. Appl. Phys., 2004, 95, 6810-6812.

22 S. Anders, M. F. Toney, T. Thomson, J.-U. Thiele, B. D. Therris, S. Sun and C. B. Murray, J. Appl. Phys., 2003, 93, 7343-7345. 
23 B. Stahl, N. S. Gajbhiye, G. Wilde, D. Kramer, J. Ellrich, M. Ghafari, H. Hahn, H. Gleiter, J. Weissmüller, R. Würschum and P. Schlossmacher, Adv. Mater., 2002, 14, 24-27.

24 M. Nakaya, M. Kanehara and T. Teranishi, Langmuir, 2006, 22, 34853487.

25 S. Saita and S. Maenosono, Chem. Mater., 2005, 17, 6624-6634.

26 (a) N. Shukla, E. B. Svedberg, J. Ell and A. J. Roy, Mater. Lett., 2006, 60, 1950-1955 (b) M. Chen, J. Kim, J. P. Liu, H. Fan and S Sun, $J$. Am. Chem. Soc., 2006, 128, 7132-7133. 